\title{
Comparison of New Multilevel Association Rule Algorithm with MAFIA
}

\author{
Arpna Shrivastava \\ Research Scholar, SATI, Vidisha (M.P.), India \\ arpna.10878@gmail.com \\ R. C. Jain \\ Director, SATI, Vidisha (M.P.), India \\ Ajay Kumar Shrivastava \\ Associate Profes sor, KIET, Ghaziabad (U.P.), India
}

\begin{abstract}
Multilevel association rules provide the more precise and specific information. Apriori algorithm is an established algorithm for finding association rules. Fast Apriori implementation is modified to develop new algorithm for finding frequent item sets and mining multilevel association rules. MAFIA is another established algorithm for finding frequent item sets. In this paper, the performance of this new algorithm is analyzed and compared with MAFIA algorithm.
\end{abstract}

Index Terms-Running Time; Multiple-Level Association Rule; Fast Apriori Implementation; Minimum Support; Confidence; Data Coding; Data Cleaning; Mafia; Apriori

\section{INTRODUCTION}

Mining association rules from large data sets has been a focused topic in recent research into knowledge discovery in databases [1]. Apriori is a classic algorithm for mining frequent item sets and learning association rules of single level [2].

Mining mu ltilevel as sociation rule was first introduced in [3]. Multiple-level association rules provide more specific and concrete knowledge. Apriori based algorith $\mathrm{m}$ for multiple-level association rules from large database was presented in [4].

Mining association rules from numeric data using genetic algorithm is explored and the problems faced during the exploration are discussed in [5]. Positive and negative association rules are another aspect of association rule mining. Context based positive and negative spatio-temporal association rule mining algorith $m$ based on Apriori algorithm is discussed in [6]. Association rule generation requires scan of the whole database which is difficult for very large database. An algorith $m$ for generating Samples from large databases is discussed in [7]. An improved algorithm based on Apriori algorith m to simu late car crash is discussed in [8]

There are many algorith ms presented which are based on Apriori algorithm [9-12]. The efficiency of algorithm is based on their implementation. UML class diagram of Apriori algorithm and its Java implementation is presented in [13]. A fast implementation of Apriori algorith $m$ is presented in [14]. The central data structure used for the implementation is Trie because it outperforms the other data structure i.e. Hash tree.

Apriori algorith $\mathrm{m}$ is the best algorithm for single level association rules mining [1, 2]. The new algorithm is developed using the modification of fast implementation of Apriori algorithm. The new algorithm finds the frequent item sets and also mines the association rules of various levels. MAFIA is an established algorithm to find the maximu $m$ frequent item sets [15] and it does not give the association rules.

In this study, the performance of new algorithm for finding frequent item sets and mining different level of association rules has been analyzed and compared with MAFIA for running time to find different level frequent item sets. The different datasets available on fimi website have been used for this study [16].

This paper is organized as follows. Problem is defined in section 2. Section 3 discusses the coding of transaction database. Section 4 deals with cleaning of data if required. New algorithm is discussed in section 5. Results for running time for different datasets and comparisons with MAFIA are discussed in section 6. Section 7 deals with conclusion and future scope.

\section{PROBLEM ST ATEMENT}

The items in any super market are numbered using the barcode. It facilitated the automatic reading of item details using the barcode reader. Barcode for an item can be some logical code or just a sequence number. The transaction database of any super market contains the transaction id and the set of barcodes against each transaction id. The sample transaction table is shown in table 1 .

Table 1. Transactional database

\begin{tabular}{|c|c|}
\hline Transaction id & Barcodes \\
\hline 12345 & $\{121234,102302,876546\}$ \\
\hline 12346 & $\{121212,102302,121234\}$ \\
\hline$\ldots$ & $\ldots \ldots \ldots \ldots \ldots \ldots \ldots \ldots \ldots \ldots$ \\
\hline
\end{tabular}


The item master table contains the details of item against the each barcode. If barcode is just a sequence number then mapping of item details from item master database to transaction database is required to produce some meaningful database. Table 2 shows the sample item master database.

Table 2. Item master database

\begin{tabular}{|c|c|c|c|c|}
\hline Barcode & Category & Brand & Pack & Price (Rs.) \\
\hline 121234 & Bread & Harvest & Normal & 18 \\
\hline 121212 & Milk & Amul & $500 \mathrm{ml}$ & 22 \\
\hline$\ldots \ldots$ & $\ldots \ldots$ & $\ldots \ldots \ldots$ & $\ldots \ldots \ldots$ & $\ldots \ldots \ldots$ \\
\hline
\end{tabular}

Item master database contains the complete details of items against each barcode. The barcode 121234 represents the item category bread brand harvest, pack normal and price Rs.18/-. This item master is providing three level of concept hierarchy. First level the item category, on the second level the item brand and the third level is pack. By $3^{\text {rd }}$ level association rules, the association between normal pack harvest bread with $500 \mathrm{ml}$ amul milk will be explored. The different databases available at fimi website have been used for finding the association rules of various levels. The running time of the algorithm for finding different level association rules from different databases using fast Apriori implementation is recorded and analyzed.

\section{CODING OF DAT A}

The algorithm runs on coded database. In this study, the six digits code has been used for every item purchased. The six digits of the code has been divided into three level hierarchy so two digits per level. In this study, maximu mundred categories can be coded. Every category of item can have maximum of hundred brands and every brand for given category can have maximum of hundred packing options. This coding can be flexible in future studies. Using three tables of code and item category, brand and packs, the coding of the database has been done easily.

Sample coding scheme is shown in table 3. Every item category is represented by two digits code. By this approach, maximum of hundred item categories can be coded. So after reading the item category the program which is responsible to generate the codes will generate two digits code for every item category.

Table 3. Coding scheme for item categories

\begin{tabular}{|c|c|c|}
\hline S.No. & Item & Code \\
\hline 1 & Milk & 10 \\
\hline 2 & Bread & 11 \\
\hline 3 & Biscuit & 12 \\
\hline 4 & Butter & 13 \\
\hline 5 & Atta & 14 \\
\hline
\end{tabular}

Table 4 is showing the sample coding scheme for different brands of item category for milk. So every item category can have hundred brands. The program which is responsible to generate the code will put two dig its code for the brand name of item category. For example, the code for brand amul of item category milk is 20 .

The table 5 is showing the sample code for packing options of items. Generally item comes in various packing options. By this coding scheme, maximum of hundred packing option are available to code the packing options for every brand of ite m category. For example the code for $200 \mathrm{ml}$ pack of brand amul of item category milk is 102000 .

Table 4. Coding scheme for brands of item category milk

\begin{tabular}{|c|c|c|}
\hline S.No. & Item & Code \\
\hline 1 & Amul & 20 \\
\hline 2 & Mother Dairy & 21 \\
\hline 3 & Sanchi & 22 \\
\hline 4 & Paras & 23 \\
\hline 5 & Jersey & 24 \\
\hline
\end{tabular}

Table 5. Coding scheme for packs of brand amul item category milk

\begin{tabular}{|c|c|c|}
\hline S.No. & Item pack $(\mathbf{m l})$ & Code \\
\hline 1 & 200 & 00 \\
\hline 2 & 500 & 01 \\
\hline 3 & 1000 & 02 \\
\hline 4 & 2000 & 03 \\
\hline
\end{tabular}

The complete coding scheme of items is shown in table 6. The program will generate six digits code for every item purchased. For example, 102101 is the code for item category milk, item brand mother dairy and packing of $500 \mathrm{ml}$. The results of this algorithm are running on datasets will come in the form of frequent ite $\mathrm{m}$ sets and association rules of $3^{\text {rd }}$ level. The result will be decoded easily using these three tables.

Table 6. Coding scheme for milk with brands

\begin{tabular}{|c|c|c|}
\hline S.No. & Item with brand & Code \\
\hline 1 & Amul Milk $200 \mathrm{ml}$ & 102000 \\
\hline 2 & Mother dairy milk $500 \mathrm{ml}$ & 102101 \\
\hline 3 & Sanchi Milk $200 \mathrm{ml}$ & 102200 \\
\hline 4 & Paras Milk $1000 \mathrm{ml}$ & 102302 \\
\hline 5 & Jersey Milk $2000 \mathrm{ml}$ & 102403 \\
\hline
\end{tabular}

Table 7 is displaying the sample transaction table of any super market. Transaction id is assigned against each purchase from the store. For example, the first customer purchases the milk of a mul brand in $200 \mathrm{ml}$ pack, bread of harvest brand in normal pack and ashirvad atta in $2 \mathrm{~kg}$ pack.

The program which is responsible to code the database will generate the data.dat file for the coded database. Each row of this file contains the one row of transaction table. The row number will represent the transaction id and the contents of the row will represent the item purchased against that transaction id. The sample of data.dat file is shown in Fig. 1.

I.J. Intelligent Systems and Applications, 2014, 11, 75-81 
Table 7. Transaction table

\begin{tabular}{|c|c|}
\hline Tid & Item purchased \\
\hline 1 & $\{$ Milk(Amul200ml)),Bread(Harvest(normal)), Atta(Ashirvad(2 kg))\} \\
\hline 2 & $\{$ Bread(Britania(big pack)), Biscuit(Britania(100gm)),Noodles(Maggi(small)) $\}$ \\
\hline 3 & $\{\operatorname{Milk}($ Amul $(500 \mathrm{ml}))$, Bread(Britania(normal)), Biscuit $($ Parle $(100 \mathrm{gm}))\}$ \\
\hline 4 & $\{$ Milk(Mother Dairy(200ml)), Bread(Harvest(normal)),Atta(Ashirvad(2 kg))\} \\
\hline 5 & $\{\operatorname{Milk}(\operatorname{Amul}(200 \mathrm{ml})), \operatorname{Bread}($ Harvest(normal)), Biscuit $(\operatorname{Parle}(100 \mathrm{gm}))\}$ \\
\hline
\end{tabular}

\begin{tabular}{|lll|}
\hline 102000 & 113001 & 135002 \\
113102 & 124002 & 146000 \\
102001 & 113101 & 124202 \\
102100 & 113001 & 135002 \\
102000 & 113001 & 124202 \\
\hline
\end{tabular}

Fig. 1. Data.dat file

This is the input file for the new algorithm. The implementation of this new algorithm will produce the frequent item sets and then the association rules of $3^{\text {rd }}$ level. Similarly input file for $2^{\text {nd }}$ level association rules is created and used to find frequent item sets and produce $2^{\text {nd }}$ level association rules.

\section{CLEANING OF DAT A}

Cleaning of data is required for the databases which are already available in coded form. Another program has been developed for cleaning the data files. The program takes the data.dat file as input and done the cleaning process. It fills the missing digits by copying the digits which are available within the code. After the cleaning process, it generates the new data.dat file which has all six digits codes.

The program reads the every code from data.dat file and counts the digits of the code. If code is less than six digits it makes the code of six digits by adding the mis sing digits from the code.

The algorith $m$ of data cleaning takes the data.dat file as input and $\mathrm{N}$ as the number of required dig its in the output file. It opens in read mode and creates and opens out.dat file in write mode. It reads the data.dat file and checks for space and new line character. These characters are the separators between two codes. It stores these codes and writes them into out.dat. It also adds the missing digits to the code, if the count of the code is less than required digits.

This algorithm return out.dat file which have all $\mathrm{N}$ digits code into it. It completes our data cleaning process. It is a complete input file so our algorithm for finding frequent item sets and association rules will work properly.

\section{ALGORITHM}

Apriori algorithm is a classic algorithm for finding frequent item sets and single level association rules [4].
A fast implementation of Apriori algorithm is presented using the trie data structure in [8]. Bodon implementation generates frequent item sets and association rules of single level. It does not generate the association rules of second level.

This Bodon implementation has been modified for finding the association rules of second level. To facilitate the process of finding the level of association rules one argument to the procedure has been added. The necessary modifications are also done to process this new argument. One additional procedure is added to separate the code of input file. After separating the coded inputs, it calls the procedure to generate the association rules according to their required level.

\section{RESULTS}

The new algorithm for finding frequent item sets and mining multiple-level association rules has been run on the four datasets which are available on fimi website[16]. The results are recorded for level-1, level-2 and level-3 for different minimum support for both algorithms i.e. new algorithm and MAFIA. Every reading is recorded after taking the average of three observations. Minimum support has been varied from 0.50 to 0.01 . Observations show that running time is increasing with levels and decreasing minimum support. The system used to run the algorith $m$ has Core 2 Duo $(1.6 \mathrm{GHz})$ processor, and one gigabyte of RAM. The operating system is Red Hat Linux. Clock function is used to calculate the running time in both the algorithms. New algorithm is used for finding the second and third level association rules and fast Apriori implementation given by Bodon has been used for find ing the first level association rules. The used datasets T10ID100K and T40I10D100K were generated by the IBM Almaden Quest research group. The Kosarak dataset was provided by Ferenc Bodon and contains (anonymized) click-stream data of a hungarian on-line news portal. The Retail dataset was donated by Tom Brijs and contains the (anonymized) retail market basket data from an anonymous Belgian retail store. Data cleaning has been done for finding second and third level association rules. The running time of new algorithm includes the generation of frequent item sets and association rules while the running time of MAFIA includes only the time to find the frequent item sets.

Table 8 shows the results for T10ID100K dataset for new algorithm and table 9 shows the results for MAFIA.

Fig. 3 shows the graph for level 1 on T10ID100K dataset. Minimum support is plotted on axis-x and 
running time is plotted on axis-y. The new algorith $m$ is performing better for low minimum support while the MAFIA is performing better for minimum support 0.05 and 0.03 .

Table 8. Running time of new algorithm for T10ID100K

\begin{tabular}{|c|c|c|c|}
\hline \multirow{2}{*}{ Min Support } & \multicolumn{3}{|c|}{ Running Time (Seconds) } \\
\cline { 2 - 4 } & Level 1 & level 2 & level 3 \\
\hline 0.50 & 0.38 & 0.44 & 0.51 \\
\hline 0.05 & 0.76 & 0.93 & 1.04 \\
\hline 0.03 & 0.86 & 1.02 & 1.17 \\
\hline 0.02 & 1.00 & 1.15 & 1.30 \\
\hline 0.01 & 1.28 & 1.45 & 1.59 \\
\hline
\end{tabular}

Table 9: Running time of MAFIA for T10ID100K

\begin{tabular}{|c|c|c|c|}
\hline \multirow{2}{*}{ Min Support } & \multicolumn{3}{|c|}{ Running Time (Seconds) } \\
\cline { 2 - 4 } & Level 1 & level 2 & level 3 \\
\hline 0.50 & 0.38 & 0.48 & 0.67 \\
\hline 0.05 & 0.36 & 0.50 & 0.69 \\
\hline 0.03 & 0.51 & 0.65 & 0.83 \\
\hline 0.02 & 1.36 & 1.52 & 1.71 \\
\hline 0.01 & 4.89 & 5.02 & 5.18 \\
\hline 0.001 & 21.76 & 29.98 & 24.97 \\
\hline
\end{tabular}

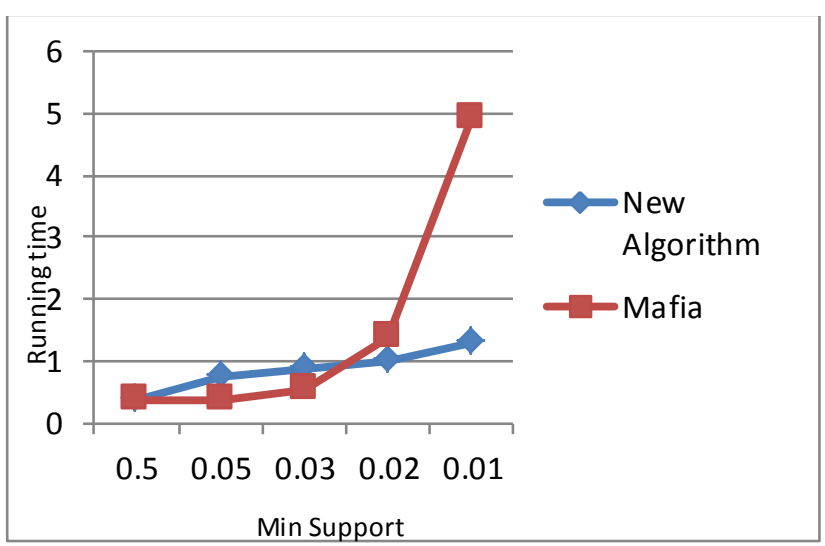

Fig. 2. Graph of running time for level 1 on T10ID100K

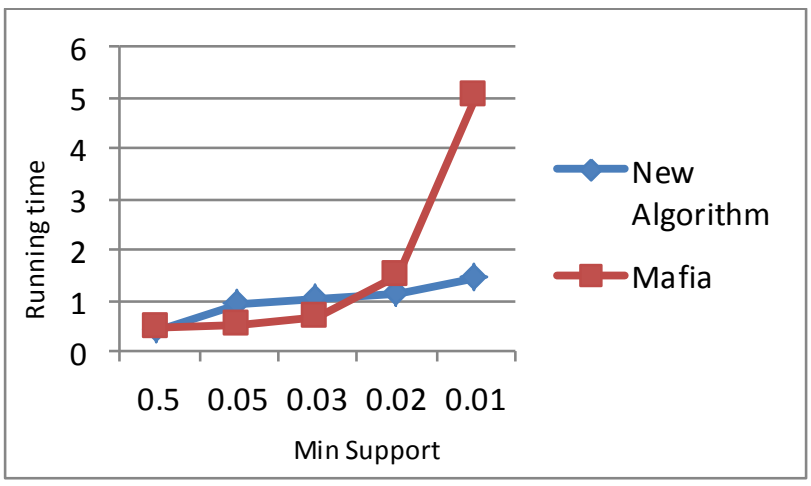

Fig. 3. Graph of running time for level 2 on T10ID100K
Similarly, Fig. 4 and Fig. 5 show the graph for level 2 and level 3 of running time on T10ID100K dataset.

Table 10 shows the results of running time for new algorith $\mathrm{m}$ on T40I10D100K dataset and table 11 shows the results of running time on the same dataset for different levels.

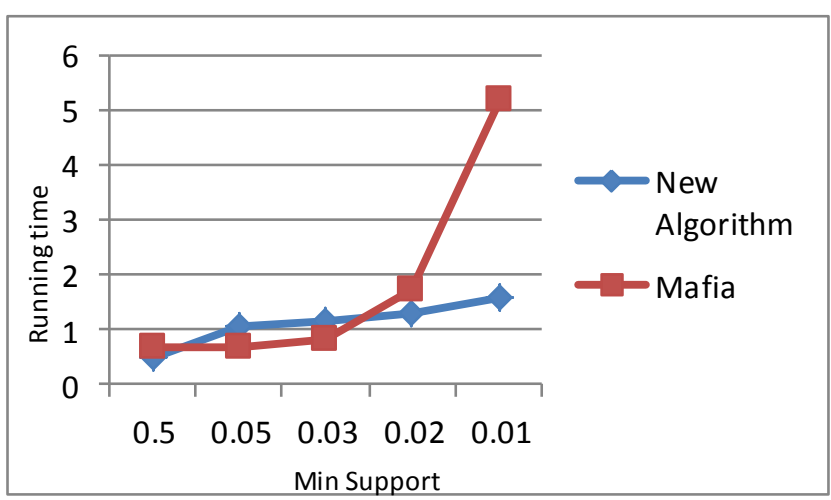

Fig. 4. Graph of running time for level 3 on T10ID100K

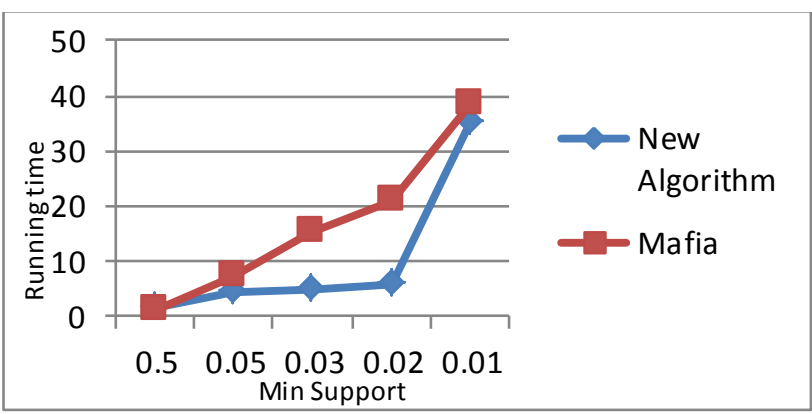

Fig. 5. Graph of running time for level 1 on T40I10D100K

Table 10. Running time of new algorithm for T40I10D100K dataset

\begin{tabular}{|c|c|c|c|}
\hline \multirow{2}{*}{ Min Support } & \multicolumn{3}{|c|}{ Running Time (Seconds) } \\
\cline { 2 - 4 } & Level 1 & level 2 & level 3 \\
\hline 0.50 & 1.42 & 1.64 & 1.90 \\
\hline 0.05 & 4.37 & 4.91 & 5.32 \\
\hline 0.03 & 5.02 & 5.50 & 6.00 \\
\hline 0.02 & 5.99 & 6.57 & 7.07 \\
\hline 0.01 & 35.26 & 36.14 & 36.29 \\
\hline
\end{tabular}

Table 11. Running time of MAFIA for T40I10D100K

\begin{tabular}{|c|c|c|c|}
\hline \multirow{2}{*}{ Min Support } & \multicolumn{3}{|c|}{ Running Time (Seconds) } \\
\cline { 2 - 4 } & Level 1 & level 2 & level 3 \\
\hline 0.50 & 1.30 & 1.67 & 2.28 \\
\hline 0.05 & 7.37 & 7.73 & 8.45 \\
\hline 0.03 & 15.24 & 15.43 & 15.86 \\
\hline 0.02 & 20.96 & 20.71 & 21.46 \\
\hline 0.01 & 38.51 & 38.32 & 38.98 \\
\hline
\end{tabular}

Fig. 6 shows the graph for level 1 on T40I10D100K dataset. The new algorith $\mathrm{m}$ is performing better for low 
values of minimum support. Similar results are shown for level 2 and level 3 which are shown in Fig. 7 and Fig. 8 respectively.

Table 12 shows the results for new algorithm for Kosarak dataset and table 13 shows the running time for Kosarak dataset for different levels.

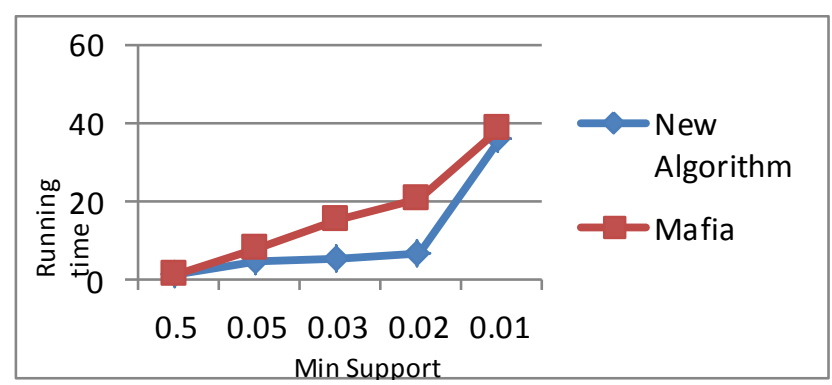

Fig. 6. Graph of running time for level 2 on T40I10D100K

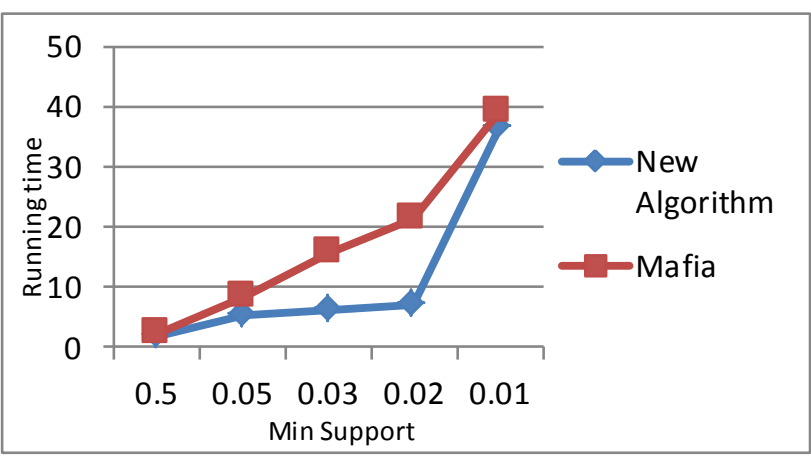

Fig. 7. Graph of running time for level 3 on T40I10D100K

Table 12. Running time of new algorithm for Kosarak

\begin{tabular}{|c|c|c|c|}
\hline \multirow{2}{*}{ Min Support } & \multicolumn{3}{|c|}{ Running Time (Seconds) } \\
\cline { 2 - 4 } & Level 1 & level 2 & level 3 \\
\hline 0.50 & 0.84 & 0.88 & 1.02 \\
\hline 0.05 & 1.82 & 1.95 & 2.17 \\
\hline 0.03 & 1.86 & 1.95 & 2.19 \\
\hline 0.02 & 1.92 & 2.02 & 2.26 \\
\hline 0.01 & 2.10 & 2.19 & 2.43 \\
\hline
\end{tabular}

Fig. 9 shows the graph between running time and minimum support for new algorithm and MAFIA algorithm and for this dataset. MAFIA algorithm is performing better. Similar results are also shown for level 2 and level 3 in Fig. 10 and Fig. 11 respectively.

Table 13. Running time of MAFIA for Kosarak dataset

\begin{tabular}{|c|c|c|c|}
\hline \multirow{2}{*}{ Min Support } & \multicolumn{3}{|c|}{ Running Time (Seconds) } \\
\cline { 2 - 4 } & Level 1 & level 2 & level 3 \\
\hline 0.50 & 0.78 & 0.94 & 1.25 \\
\hline 0.05 & 0.79 & 0.95 & 1.26 \\
\hline 0.03 & 0.80 & 0.95 & 1.27 \\
\hline 0.02 & 0.84 & 0.98 & 1.29 \\
\hline 0.01 & 1.00 & 1.13 & 1.46 \\
\hline
\end{tabular}

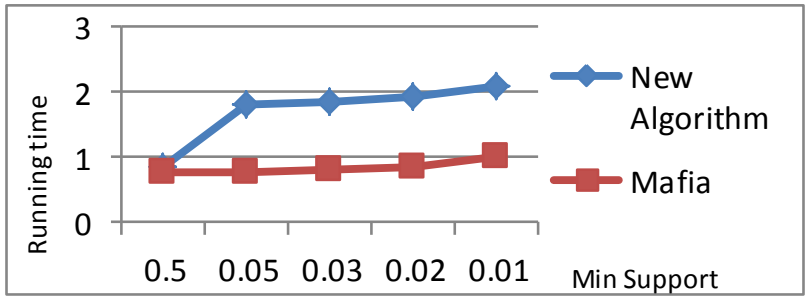

Fig. 8. Graph of running time for level 1 on Kosarak

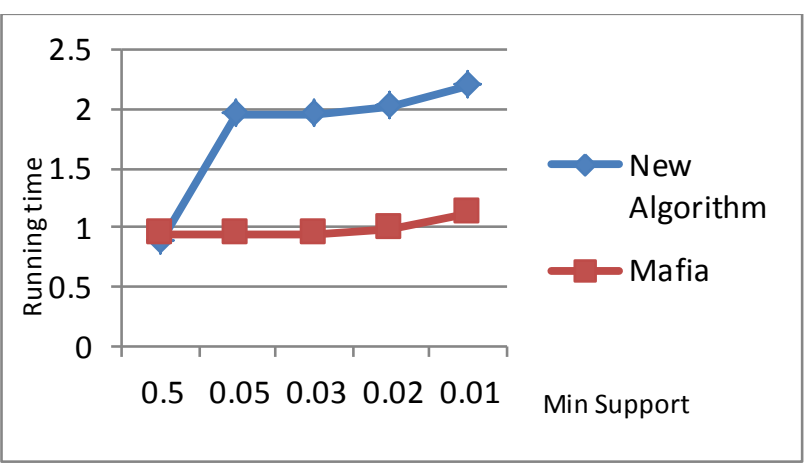

Fig. 9. Graph of running time for level 2 on Kosarak

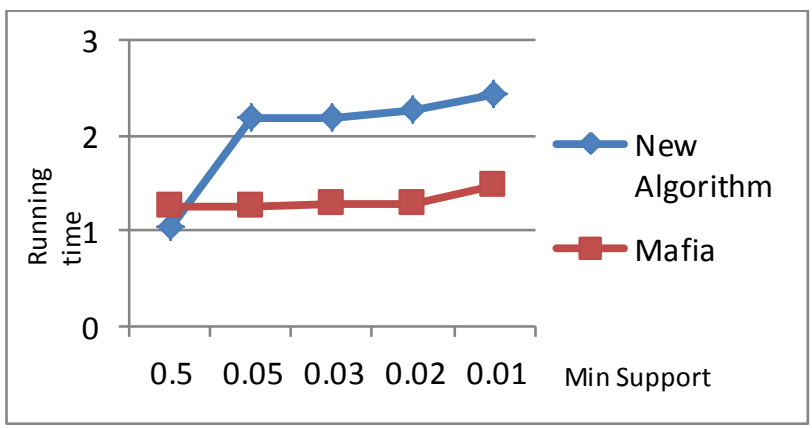

Fig. 10. Graph of running time for level 3 on Kosarak

Table 14 shows the results for new algorithm on Retail dataset. Table 15 shows the same results for MAFIA algorithm.

Table 14. Running time of new algorithm for Retail

\begin{tabular}{|c|c|c|c|}
\hline \multirow{2}{*}{ Min Support } & \multicolumn{3}{|c|}{ Running Time (Seconds) } \\
\cline { 2 - 4 } & Level 1 & level 2 & level 3 \\
\hline 0.50 & 0.36 & 0.40 & 0.47 \\
\hline 0.05 & 0.73 & 0.84 & 0.99 \\
\hline 0.03 & 0.74 & 0.86 & 1.00 \\
\hline 0.02 & 0.75 & 0.87 & 1.01 \\
\hline 0.01 & 0.81 & 0.96 & 1.08 \\
\hline
\end{tabular}

Table 15. Running time of MAFIA for Retail

\begin{tabular}{|c|c|c|c|}
\hline \multirow{2}{*}{ Min Support } & \multicolumn{3}{|c|}{ Running Time (Seconds) } \\
\cline { 2 - 4 } & Level 1 & level 2 & level 3 \\
\hline 0.50 & 0.37 & 0.45 & 0.61 \\
\hline 0.05 & 0.38 & 0.46 & 0.61 \\
\hline 0.03 & 0.39 & 0.46 & 0.62 \\
\hline 0.02 & 0.40 & 0.46 & 0.62 \\
\hline 0.01 & 0.49 & 0.65 & 0.75 \\
\hline
\end{tabular}

I.J. Intelligent Systems and Applications, 2014, 11, 75-81 
Fig. 12 shows the results for level 1.The new algorith $m$ takes the time to generate the frequent item sets and mining the association rules. So for this dataset, the performance of new algorithm is acceptable. Fig. 13 shows the same results for level 2 and Fig. 14 shows the graph for level 3.

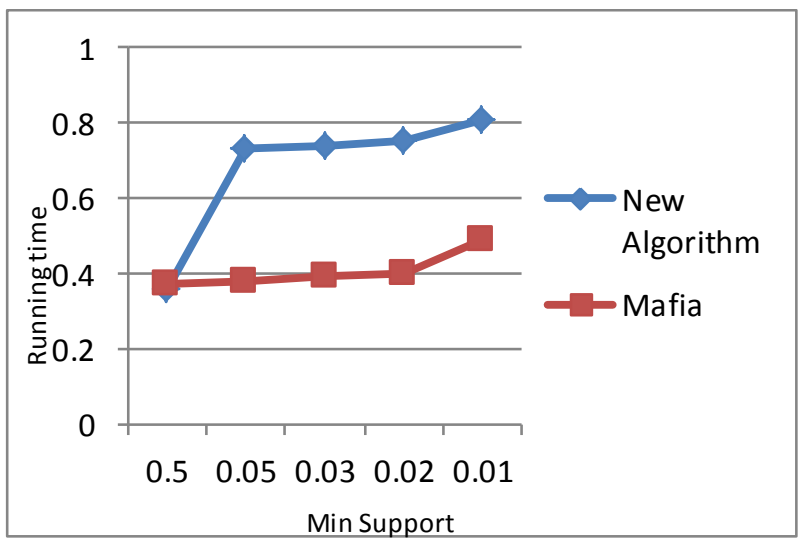

Fig. 11. Graph of running time for level 1 on Retail

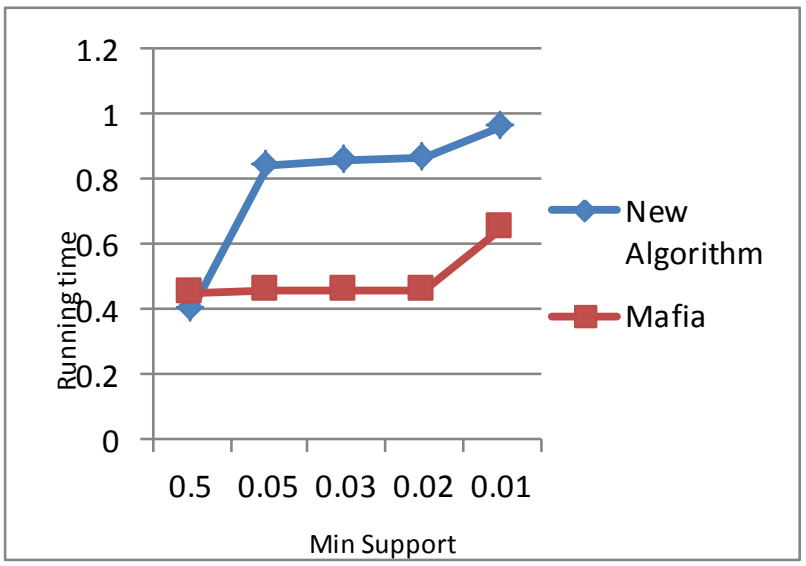

Fig. 12. Graph of running time for level 2 on Retail

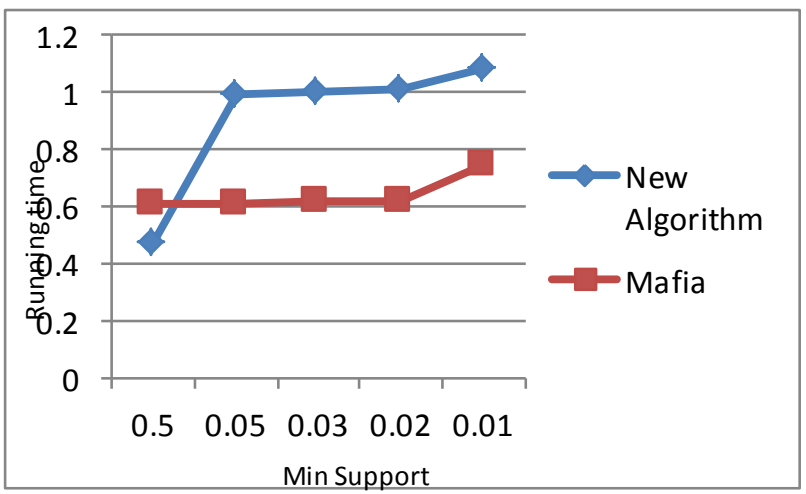

Fig. 13. Graph of running time for level 3 on Retail

The new algorith $\mathrm{m}$ is generating the frequent item sets and association rules so time taken by new algorith $m$ to generate the association rules is a considerable time. When this time is considered, the performance of new algorithm will be better. Hence the results of the new algorith $m$ are acceptable. Time required for cleaning the dataset is not included in the recorded running time.

\section{CONCLUSION AND FUTURE SCOPE}

The different datasets available on Frequent Itemset Mining Dataset Repository (fimi) has been used in this study. The data cleaning has been done before executing the implementation of algorith $\mathrm{m}$ for finding second and third level association rules. The new algorithm for finding frequent item sets and mining different level association rules is executed on different datasets and running time is recorded for different level of association rules with varying minimu m support for both algorith ms i.e. new algorithm and MAFIA. The results are acceptable as new algorithm has outperformed the MAFIA algorithm for first two datasets and after considering the time required to mine association rules. Other results are also acceptable. This comparison study can be extended for different implementations in future.

\section{REFERENCES}

[1] R. Agrawal, T. Imielinski; A. Swami: Mining Association Rules Between Sets of Items in Large Databases", SIGMOD Conference 1993, pp. 207-216.

[2] RAgrawal et al.(1994), Fast Algorithms for Mining Association Rules, Proceedings of the 20th International Conference on Very Large Data Bases, 1994, pp. 487-499.

[3] J. Han, Y. Fu, "Discovery of Multiple-Level Association Rules from Large Database", Proceeding of the 21st VLDB Conference Zurich, Swizerland, 1995, pp.420-431.

[4] J. Han, Y. Fu, "Mining Multiple-Level Association Rules in Large Database", IEEE transactions on knowledge \& data engineering in 1999, pp.1-12.

[5] B. Minaei-Bidgoli, R. Barmaki, M. Nasiri, "Mining numerical association rules via multi-objective genetic algorithms", Information Sciences (233), Elsevier, 2013, pp.15-24.

[6] M. Shaheen, M. Shahbaz, A. Guergachi, "Context based positive and negative spatio-temporal association rule mining", Knowledge-Based Systems (37), Elsevier, 2013, pp. 261-273.

[7] B. Chandra, S. Bhaskar, "A new approach for generating efficient sample from market basket data", Expert Systems with Applications (38), Elsevier, 2011, pp. 1321-1325.

[8] L. Xiang, "Simulation System of Car Crash Test in CNCAP Analysis Based on an Improved Apriori Algorithm", International Conference on Solid State Devices and Materials Science, Physics Procedia (25), Elsevier, 2012, pp. 2066- 2071.

[9] R. Agrawal, H. Mannila, R. Srik ant, H. Toivonen, and A. I. Verkamo. Fast discovery of association rules. In Advances in Knowledge Discovery and Data Mining, 1996, pp. 307.328.

[10] Bing Liu, Wynne Hsu and Yiming Ma, "Mining association rules with multiple minimum supports", ACM SIGKDD International Conference on Knowledge Discovery \& Data Mining, 1999, pp.337-341. 
[11] F. Berzal, J. C. Cubero, Nicolas Marin, and Jose-Maria Serrano, "TBAR: An efficient method for association rule mining in relational databases", Data and Knowledge Engineering 37, 2001, pp.47-64.

[12] N. Rajkumar, M.R. Kartthik and S.N. Sivanandam, "Fast Algorithm for Mining Multilevel Association Rules", Conference on Convergent Technologies for the AsiaPacific Region, TENCON, 2003, pp.688-692.

[13] Y. Li, "The Java Implementation of Apriori algorithm Based on Agile Design Principles", 3rd IEEE International Conference on Computer Science and Information Technology (ICCSIT), 2010, pp. 329-331.

[14] F. Bodon, "Fast Apriori Implementation", Proceedings of the IEEE ICDM Workshop on Frequent Itemset Mining Implementations, 2003.

[15] Doug Burdick, Manuel Calimlim and Johannes Gehrke, "M AFIA: A Maximal Frequent Itemset Algorithm for TransactionalDatabases" In Proceedings of the 17th International Conference on Data En gineering. Heidelberg, Germany, April 2001.

[16] "http://fimi.ua.ac.be/data/".

\begin{abstract}
Authors' Profiles
Arpna Shrivastava is a research scholar in Barkatullah University, Bhopal (M.P.). She has done MCA from MD University, Rohtak and M.Sc. (CS) from Barkatullah University, Bhoapl. She has published various research papers in conferences and journals.
\end{abstract}

Dr. R. C. Jain is working as Director of Samrat Ashok Technological Institute, Vidisha (M.P.). He has more than 20 $\mathrm{yrs}$ of research experience. He has published 140+ research papers in various conferences and refereed journals.

Dr. Ajay Kumar Shrivastava is working as Associate Professor in Department of Computer Applications, Krishna Institute of Engineering and Technology, Ghaziabad. He has done his Ph.D. and MCA degrees from UTD Campus, Dr. H.S.Gour University (A Central University), Sagar (M.P.). He has published various research papers in journals and conferences.

How to cite this paper: Arpna Shrivastava, R. C. Jain, Ajay Kumar Shrivastava,"Comparison of New Multilevel Association Rule Algorithm with MAFIA", International Journal of Intelligent Systems and Applications(IJISA), vol.6, no.11, pp.75-81, 2014. DOI: $10.5815 /$ ijisa.2014.11.10 